\title{
The Effects of Business Intelligence on Strategic Management of Enterprises
}

\author{
Ezgi Dinçerden \\ Marmara University, Istanbul, Turkey
}

\begin{abstract}
Discipline of informatics must contain one of the significant issues that need to develop for especially processing systems of large-scale enterprises. At this point, a well-designed business intelligence (BI) system, which includes a structure of regular business activities and analyses within whole an enterprise, requires to manage stored data and transform the data into information as an output and forecasting targets and provide sustainable growth for an enterprise or an organization. Information systems (IS) support to constitute these processes by using the information technologies (IT) that cause to capture data which will be transformed into information and integrate whole subsystems that need to develop for all departments of the enterprise. BI tools organize all parts of these business analysis and processes and effect on the top management level of enterprises or organizations. Decision makers at the top-level of management must use these information and knowledge to orient future decisions for the enterprise that includes investments, company policies, precautions for the future negations, etc. This study shows that the BI is not only an IS, but also reinforcement for strategic decisions of the enterprises and/or organizations.
\end{abstract}

Keywords: business intelligence (BI), information systems (IS), information technologies (IT), data, data mining, data warehousing, business systems, strategic decisions

\section{Introduction}

Main purpose of this study is to explain business intelligence (BI) as a new perspective and framework for enterprises. More specifically, definition of the BI is examined in a different context that includes a relationship between the BI and strategic decisions of an enterprise. In this context, information systems (IS) including processing data, information, and knowledge will be clarified as a part of the BI systems. IS are technical phase involved data warehousing, data mining, and system analysis.

\section{Literature Review}

Literature research for this study is formatted by some critical situations as follows: (1) All resources predicate on statements of the information technologies (IT) which are associated with the BI systems; (2) the IS items used for developing business processes of an enterprise are considered as connection with functions of inter-departments within the enterprise; and (3) the resources were chosen according to a practical and basic infrastructure of the IS that can be adapted for rapidly changing IT tools.

In addition to this, all technological issues require also an empirical approach to manage several stages for

Ezgi Dinçerden, Ph.D., MOS master instructor, Marmara University, Istanbul, Turkey.

Correspondence concerning this article should be addressed to Ezgi Dinçerden, Nisantasi Campus, Faculty of Communication, Marmara University, Istanbul, Turkey. 
end-users in the enterprise in order to adjust the business systems more effectively. Therefore, particularly the top-level managers must follow the developments about the BI techniques.

\section{Theory and Research Results}

\section{The IS Towards BI}

Nowadays, especially big and middle-scale enterprises need to develop their business systems in order to decrease costs and save time during their business processes. To manage an enterprise's data, attendantly information and knowledge by using IT require continuous improvement. At this point, the data processing emerges to collect, transform it into information, and discover qualified knowledge for future decisions of the enterprise in the long term.

Gathering, cleaning, and restructuring the data which are parts of data mining techniques like classification, such as algorithms of decision trees, neural networks, clustering, prediction, and association rules, such as market basket analysis, are considerable in parts of analyzing the data and discovering the knowledge for building a BI system into the enterprise (Dinçerden, 2010).

Figure 1 shows that system stages included feasibility, analysis, design, implementation, and maintenance (Yeates \& Wakefield, 2004) which cause to reveal a well-designed system to manage business processes. Each stage has different specialities according to system analysts and/or IT developers to establish an influential information system.

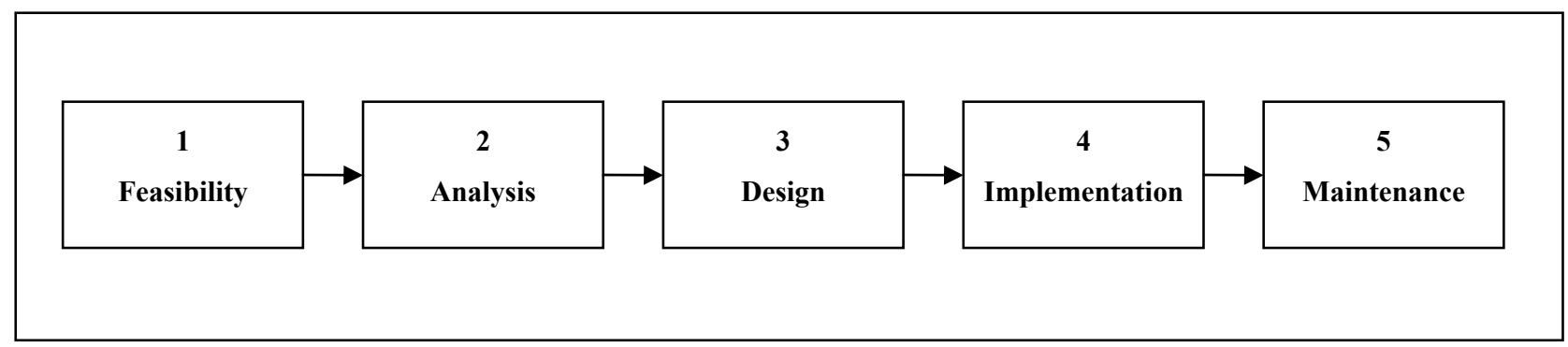

Figure 1. Stages in system development. Source: Yeates and Wakefield (2004).

Main IS components included input, output, models, control, technology, and database arrange of the whole data of an enterprise to obtain consistent estimates for especially top-level executive decisions of an enterprise. Processing the data requires a well-designed information system that enables to form the data within database management systems (Dinçerden, 2015). After collecting and processing the data, outputs that guide prudential top-level management decisions can be managed by decision-makers. In this context, the major influential factors of the IS are specified as follows (Burch \& Grudnitski, 1990):

(1) data processing requirements;

(2) system requirements;

(3) information quality and usability;

(4) competitive forces;

(5) user/system interface;

(6) cost-effectiveness requirements;

(7) feasibility requirements;

(8) organizational factors; 
(9) integration;

(10) human factors.

In this context, data source types separated as operational, private, and external are handled in database management systems. The operational data involve financial, logistics, sales, order entry, personnel, billing, research, and engineering. The private data concern with product analysis spreadsheets, regional product usage spreadsheets, and prospective customer databases. The external data can be counted as health care statistics, customer profile information, and customer credit reports (Moss \& Atre, 2003).

The data analysis that needs to develop consistently is built by using data management techniques, such as online analytical processing (OLAP), relational online analytical processing (ROLAP), and multidimensional analytical processing (MOLAP) in order to attain real-time reports of the business process regularly (Turban, Sharda, Delen, \& King, 2011). Thus, these analyses are stated like basic supporting activities of the BI during business process of an organization.

\section{The BI and Strategic Decisions}

The BI platform manages the data and transforms them into information by using IT tools and applications within an organization. So that it causes to attain outputs as business reports which affected forward-looking decisions of the enterprise.

One of the important issues of making decision for strategic goals is analyzed into two stages as design and execution according to internal and external analysis (Forgang, 2004). According to this describing, design stage determines choices to differentiate enterprise's good and/or service to get competitive advantage versus its other rivals. The execution stage is related to functional area decisions that the enterprise implements (Forgang, 2004).

A well-designed BI system prepares the accumulated data for processing and transforming information and discovering the qualified knowledge by using extract, transform, and load (ETL or ELT) phases. This process of transforming the data to the information requires BI techniques, such as data warehousing and data mining during accessing the information as an output which will be used for strategic decisions of an enterprise in the long-term.

Figure 2 shows a sample model how a BI system progresses with its components. In addition to this, BI architecture as a tool of a project process must adopt each of the project phases, such as requirements gathering, solution design, test, implement, and maintenance (Howson, 2014).

BI components support connection among departments in an enterprise is facilitated by using some information system applications, such as enterprise resources planning (ERP), customer relationship management (CRM), and supply chain management (SCM). BI techniques enter into business activities to arrange whole business system and integrate each department of an enterprise, such as manufacturing, finance, marketing, sales, logistics, human resources, and accounting.

As can be seen in Figure 3, some departments of an enterprise related to the BI can be developed phase by phase, such as analysis, insight, decision, and evaluation (Vercellis, 2009). 


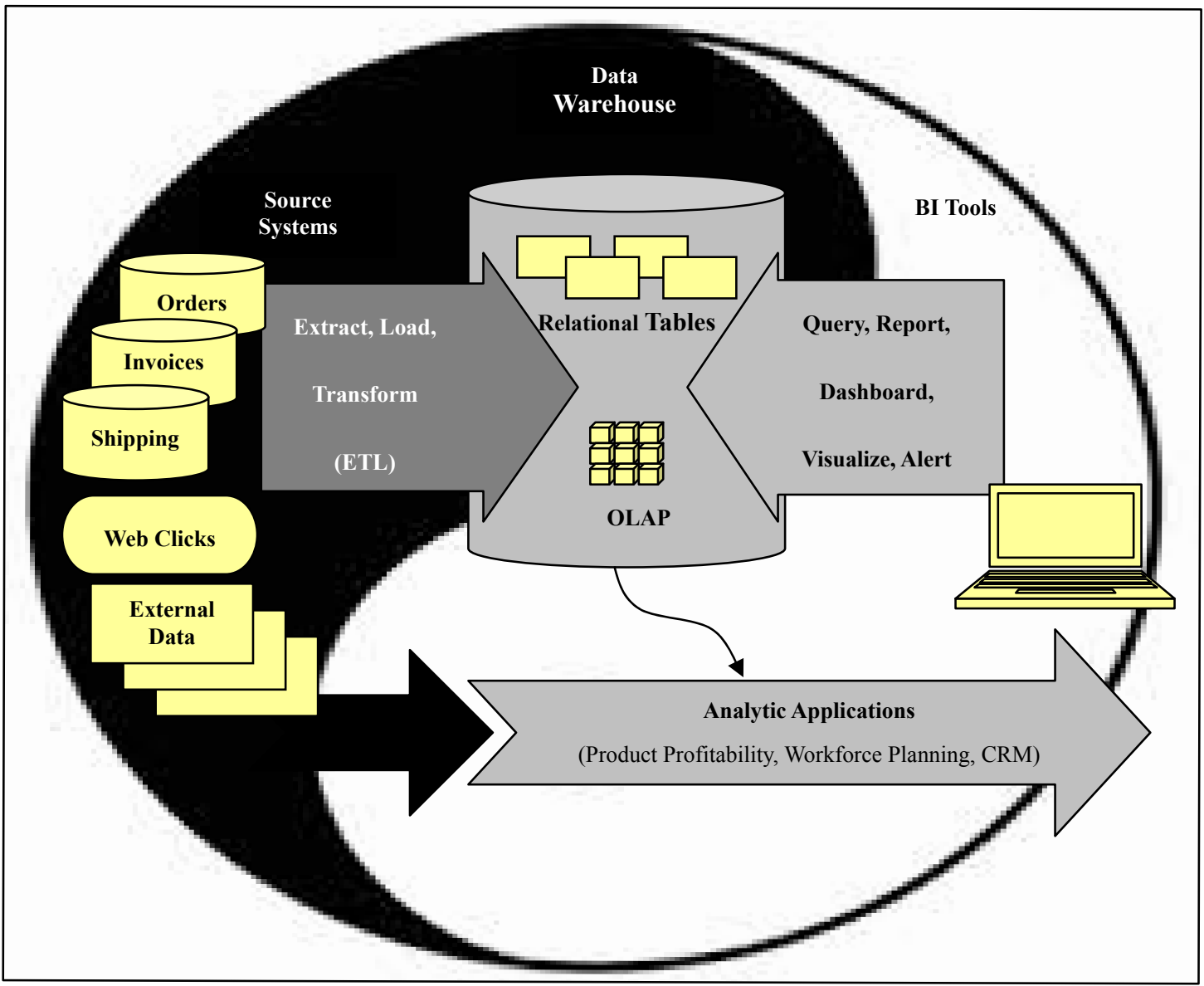

Figure 2. Major components in the BI life cycle. Source: Howson (2014).

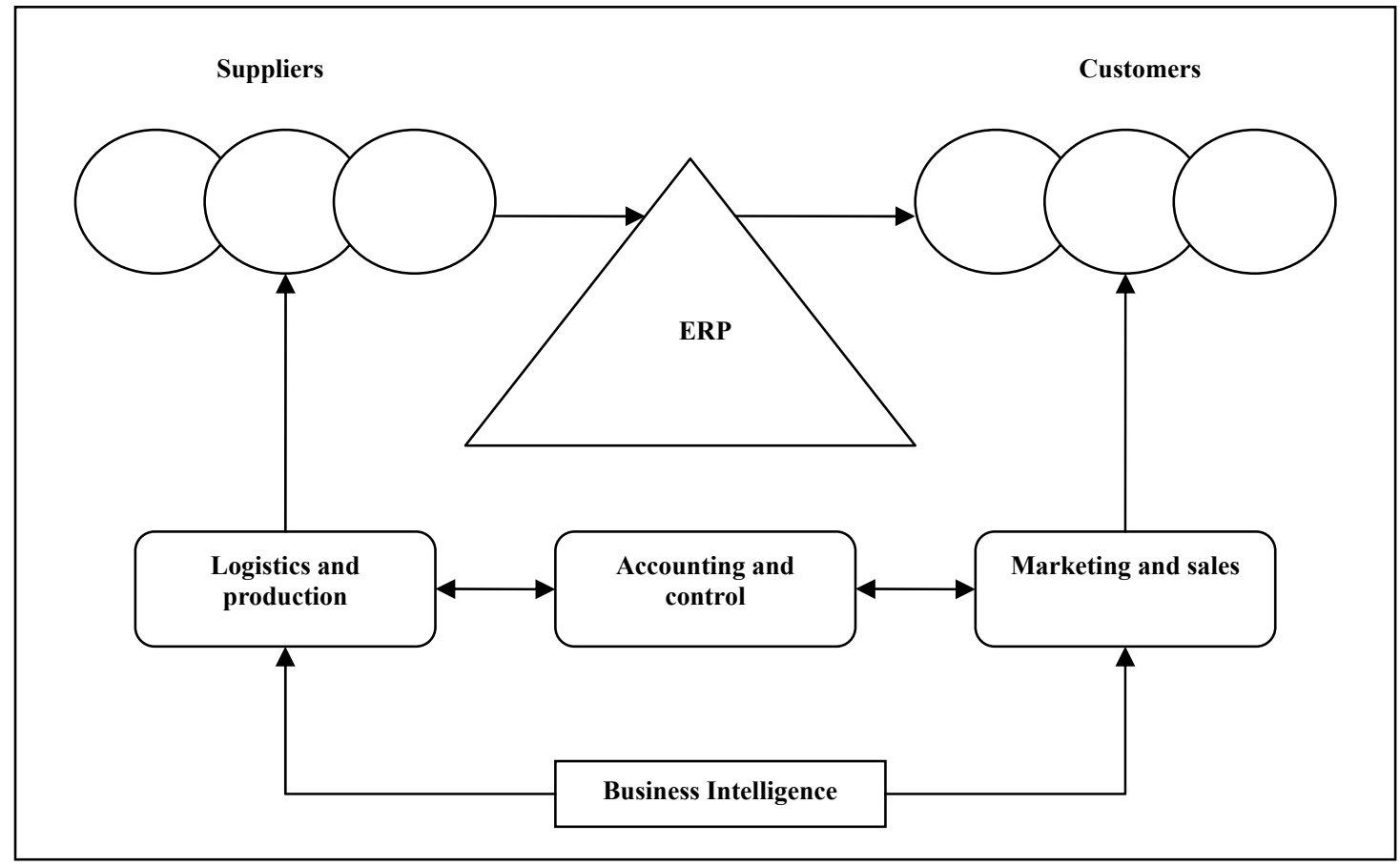

Figure 3. Departments of an enterprise concerned with business intelligence systems. Source: Vercellis (2009). 
From the point of managerial perspective, if management levels of an enterprise are accepted at three stages as operational, managerial, and executive (Valacich \& Schneider, 2010), the BI applications support managers in all aspects of forward-looking decisions. Especially, executive management is at the top-level in the enterprises that strategic decisions are made for the enterprises' sustainability.

Business strategies can be examined within four intersections as industry-wide, industry-segment focus, cost leadership, and product differentiation. These sections are focusing on maintaining quality and being fair to the customers (Gendron, 2013). The BI leads to business value that can be grouped as management, revenue generating, and resource consumption processes (S. Williams \& N. Williams, 2007). The BI allows employees to access, interact with, and analyze data in order to align business processes (Howson, 2008). Meanwhile, BI opportunities enable to challenge in terms of competitive strategies for the real-, short-, mid-, and long-term decisions.

\section{Conclusions}

BI systems are used for a part of formation of the enterprises' sustainability. Some of benefits of a BI system are to analyse all data for gaining information in their database management systems, to regulate their routine operation speedily, to decrease their costs, and to return on investments for the long term in the end of whole this progress.

The BI system included processing the data by using data warehousing and data mining techniques supports to obtain consistent and qualified information, and consequently knowledge that can be used in order to reach strategic goals and targets by end-users and executive managers in the future. In addition to this, developing IT that is significant infrastructure of the BI system gives opportunities and provides a competitive advantage in the global market for the enterprises. Thus, the enterprises must keep abreast of the new economy and digital world by using and improving new solutions.

In conclusion, the $\mathrm{BI}$ is defined as a technology that gathers, analyses, and reports the data for decision-makers in an enterprise. However, the BI is not only a technical set of business analysis, but also a complex and effective structure for strategic decisions of the enterprises directly and/or indirectly.

\section{References}

Burch, J. G., \& Grudnitski, G. (1990). Information systems: Theory and practice (5th ed.). Singapure, Canada: John Wiley \& Sons, Inc.

Dinçerden, E. (2010). The role of data mining techniques for organizations as a part of business intelligence. Proceedings from 2nd International Conference on New Media and Interactivity, April, 2010, Istanbul, Turkey.

Dinçerden, E. (2015). The role of business intelligence in strategic management of enterprises. Proceedings from 2015 Winter Global Technology Management Symposium, Riverside, California, USA.

Forgang, W. G. (2004). Strategy-specific decision making: A guide for executing competitive strategy. New York: M.E. Sharpe.

Gendron, S. M. (2013). Business intelligence applied: Implementing an effective information and communications technology infrastracture (1st ed.). Hoboken: John Wiley \& Sons, Inc.

Howson, C. (2008). Successful business intelligence, secrets to making BI a killer app (1st ed.). New York: The McGraw-Hill Companies.

Howson, C. (2014). Successful business intelligence: Unlock the value of BI \& big data (2nd ed.). New York: McGraw-Hill Education.

Moss, L. T., \& Atre, S. (2003). Business intelligence roadmap: The complete project lifecycle for decision-support applications (1st ed.). Boston, USA: Pearson Education, Inc.

Turban, E., Sharda, R., Delen, D., \& King, D. (2011). Business intelligence: A managerial approach (2nd ed.). Upper Saddle River: Pearson Education, Inc. 
Valacich, J., \& Schneider, C. (2010). Information systems today: Managing in the digital world (4th ed.). Upper Saddle River: Pearson Education, Inc.

Vercellis, C. (2009). Business intelligence: Data mining and optimization for decision making (1st ed.). Cornwall, UK: John Wiley \& Sons Inc.

Williams, S., \& Williams, N. (2007). The profit impact of business intelligence. San Francisco: Morgan Kaufmann Publishers, Elsevier Inc.

Yeates, D., \& Wakefield, T. (2004). Systems analysis and design (2nd ed.). London, UK: Pearson Education Inc. 